\title{
Association of Renal Biochemical Parameters with Left Ventricular Diastolic Dysfunction in a Community-Based Elderly Population in China: A Cross-Sectional Study
}

\author{
Jingmin Zhou ${ }^{19}$, Xiaotong Cui ${ }^{19}$, Xuejuan Jin ${ }^{19}$, Jun Zhou ${ }^{1}$, Hanying Zhang ${ }^{2}$, Bixiao Tang ${ }^{2}$, Michael Fu ${ }^{3}$, \\ Hans Herlitz ${ }^{4}$, Jie Cui ${ }^{1}$, Hongmin $\mathrm{Zhu}^{1}{ }^{1}$, Aijun Sun ${ }^{1}$, Kai Hu${ }^{1}$, Junbo $\mathrm{Ge}^{1}{ }^{*}$ \\ 1 Shanghai Institute of Cardiovascular Diseases, Zhongshan Hospital, Fudan University, Shanghai, China, 2 Fengjing Community Health Center, Jinshan District, Shanghai, \\ China, 3 Section of Cardiology, Department of Medicine, Sahlgrenska University Hospital/Östra Hospital, University of Gothenburg, Gothenburg, Sweden, 4 Section of \\ Nephrology, Department of Medicine, Sahlgrenska University Hospital/Östra Hospital, University of Gothenburg, Gothenburg, Sweden
}

\begin{abstract}
Background: Relationship of left ventricular diastolic dysfunction (LVDD) with parameters that could provide more information than hemodynamic renal indexes has not been clarified. We aimed to explore the association of comprehensive renal parameters with LVDD in a community-based elderly population.

Methods: 1,166 community residents (aged $\geq 65$ years, 694 females) participating in the Shanghai Heart Health Study with complete data of renal parameters were investigated. Echocardiography was used to evaluate diastolic function with conventional and tissue Doppler imaging techniques. Serum urea, creatinine, urea-to-creatinine ratio, estimated glomerular filtration rate (eGFR) and urinary albumin-to-creatinine ratio (UACR) were analyzed on their associations with LVDD.

Results: The prevalence of LVDD increased in proportion to increasing serum urea, urea-to-creatinine ratio and UACR. These three renal parameters were found negatively correlated to peak early $(E)$ to late $(A)$ diastolic velocities ratio $(E / A)$, and positively to left atrial volume index; UACR also positively correlated with $E$ to peak early ( $\left.E^{\prime}\right)$ diastolic mitral annular velocity ratio $\left(E / E^{\prime}\right)$. Serum urea, urea-to-creatinine ratio and UACR correlated with LVDD in logistic univariate regression analysis, and urea-to-creatinine ratio remained independently correlated to LVDD [Odds ratio (OR) 2.82, 95\% confidence interval (CI) 1.34-5.95] after adjustment. Serum urea (OR 1.18,95\%Cl 1.03-1.34), creatinine (OR 6.53, 95\%Cl 1.70--25.02), eGFR (OR 0.22, $95 \% \mathrm{Cl} 0.07-0.65)$ and UACR (OR $2.15,95 \% \mathrm{Cl} 1.42-3.24)$ were revealed independent correlates of advanced (moderate and severe) LVDD.
\end{abstract}

Conclusions: Biochemical parameters of renal function were closely linked with LVDD. This finding described new cardiorenal relationship in the elderly population.

Citation: Zhou J, Cui X, Jin X, Zhou J, Zhang H, et al. (2014) Association of Renal Biochemical Parameters with Left Ventricular Diastolic Dysfunction in a Community-Based Elderly Population in China: A Cross-Sectional Study. PLoS ONE 9(2): e88638. doi:10.1371/journal.pone.0088638

Editor: Antonio Carlos Seguro, University of São Paulo School of Medicine, Brazil

Received August 29, 2013; Accepted January 9, 2014; Published February 12, 2014

Copyright: (c) 2014 Zhou et al. This is an open-access article distributed under the terms of the Creative Commons Attribution License, which permits unrestricted use, distribution, and reproduction in any medium, provided the original author and source are credited.

Funding: This study is funded by grants from the Key Projects in the National Science \& Technology Pillar Program in the Eleventh (2006BAI01A04) and Twelfth (2011BAl11B10) Five-year Plan Period of China, and the Exchange Program Fund of Doctoral Student under the Fudan University Graduate School. The funders had no role in study design, data collection and analysis, decision to publish, or preparation of the manuscript.

Competing Interests: The authors have declared that no competing interests exist.

*E-mail: jbge@zs-hospital.sh.cn

9 These authors contributed equally to this work.

\section{Introduction}

Heart failure (HF) with preserved ejection fraction (HFPEF) has increasingly attracted attention for its high prevalence and poor prognosis [1]. Left ventricular diastolic dysfunction (LVDD) has been considered as one of the principal pathophysiologic mechanisms [2] and part of essential diagnostic indexes [3] of HFPEF. Both HFPEF and LVDD have been commonly demonstrated in aged population [4,5]. Of note, the prevalence of chronic kidney disease (CKD) [6] and the CKD-associated mortality [7] were also significantly higher in HFPEF than HF with reduced ejection fraction (HFREF) among the elderly patients. However, the association between renal function and LVDD in elderly population has not been fully clarified. It was observed that renal insufficiency was associated with LVDD in patients with [8] or without [9] symptomatic HF. But so far, studies have mainly focused on the relationship between LVDD and dynamic renal parameters including estimated glomerular filtration rate (eGFR) and creatinine clearance [6-10]. However, renal biochemical parameters such as serum urea, urea-tocreatinine ratio and urinary albumin-to-creatinine ratio (UACR) that could provide additional information than dynamic renal indexes have not yet been reported in LVDD and HFPEF. Furthermore, most former studies were carried out in hospitalized patients while little is known about general population. In the present study, we aimed to explore the association of comprehensive renal parameters including serum urea, creatinine, urea-to- 
creatinine ratio, eGFR and UACR with LVDD in a communitybased elderly population in China.

\section{Methods}

\section{Ethics statement}

The present study conforms to the ethical guidelines of the 1975 Declaration of Helsinki and was approved by the Ethics Committee of Zhongshan hospital affiliated to Fudan University. Written informed consent was obtained from each participant during recruitment.

\section{Study design and population}

This study was part of Shanghai Heart Health Study (SHHS) [11], which is an ongoing large population study to investigate the incidence, prevalence, morbidity and mortality of cardiovascular diseases in community adults of Jinshan District of Shanghai, China. From January 2007 to June 2008, 1955 community residents older than 65 years were recruited and underwent a baseline survey including general information by self-administered questionnaire, standard 12-leads electrocardiogram (EGG), chest $\mathrm{X}$-ray, and serum and urine biochemical parameters examination. The sample was followed up every 2 years. The biochemical parameters we used were measured in the first follow-up in 20092010. During the second follow-up in 2011, participants were invited to undergo an echocardiography examination. Finally 1166 participants with completed renal function and echocardiographic data were included in the present study. Those who did not have complete data from biochemical or echocardiographic analyses were excluded.

\section{Clinical, demographic and biochemical parameters}

Clinical and demographic data were obtained from questionnaires at recruitment including age, gender, smoking and education status, and previous diseases and drug therapies. Blood pressure was measured with the manual mercury sphygmomanometer after a 5 -min rest in a sitting position using phases 1 and 5 of the Korotkoff sounds for systolic and diastolic blood pressure (SBP and DBP), respectively. Height and body weight were measured simultaneously. Waist circumference was measured in midway between the lower limit of the rib cage and the iliac crest with the subject standing using a flexible and non-distensible tape. Heart rate (HR) was read out from standard 12-leads ECG measured after 5 minutes in supine position.

Coronary heart disease (CHD) was defined as a history of myocardial infarction or angina pectoris, or angiography confirmed coronary stenosis $>70 \%$. Atrial fibrillation was documented by either medical history or the ECG examination, both paroxysmal and persistent atrial fibrillation were included. Stroke was diagnosed by past cranial computed tomography or magnetic resonance imaging. Those who had smoked more than three cigarettes a day for at least one year were defined as smokers, both former and current smokers were included. Diabetes mellitus was diagnosed by definite disease history, or using of oral hypoglycemic drugs or insulin, or fasting blood glucose (FBG) $\geq 7 \mathrm{mmol} / \mathrm{l}$. Hypertension was diagnosed by persistent resting blood pressure greater than $140 / 90 \mathrm{mmHg}$, or a definite disease history. Body mass index (BMI) was calculated as weight $(\mathrm{kg}) /$ height $(\mathrm{m})^{2}$. Obesity was a BMI of $28 \mathrm{~kg} / \mathrm{m}^{2}$ or higher, or a waist circumference of at least $85 \mathrm{~cm}$ in men or $80 \mathrm{~cm}$ in women. Dyslipidemia was considered present if the subject had a definite disease history or met any of the following: total cholesterol (TC) $\geq 6.22 \mathrm{mmol} / \mathrm{l}$, triglycerides $\geq 2.26 \mathrm{mmol} / \mathrm{l}$, low-density lipo- protein cholesterol $(\mathrm{LDL}-\mathrm{C}) \geq 4.14 \mathrm{mmol} / \mathrm{l}$, or high-density lipoprotein cholesterol (HDL-G) $<1.04 \mathrm{mmol} / \mathrm{l}$.

Venous blood sample was obtained after a 12-hour-overnight fast and transferred every day to the central laboratory of Zhongshan hospital. After centrifugation and routine blood test, the serum was stored at $-80^{\circ} \mathrm{C}$ until measurement of N-terminal pro-B type natriuretic peptide (NT-proBNP) using a fully automated electrochemiluminescence sandwich immunoassay on an Elecsys 1010 (Roche Diagnostics, Basel, Switzerland). Renal function parameters, and serum glucose and lipids were assessed by standard methods. The eGFR was calculated using the modified Modification of Diet in Renal Disease (MDRD) equations recommended by the Chinese eGFR Investigation Collaboration $\left[\mathrm{eGFR}\left(\mathrm{ml} / \mathrm{min} / 1.73 \mathrm{~m}^{2}\right)=175 \times(\right.$ Serum creatinine $)^{-1.234} \times$ age $^{-0.179} \times 0.79$ (if female) (Serum creatinine: $\mathrm{mg} /$ dl, age: years)] [12]. An overnight morning urine sample was also collected to measure the urinary albumin using the immune turbidimetric method (DiaSys Diagnostic Systems, Shanghai) and the urinary creatinine using the enzymatic colorimetric method (Roche/Hitachi). The UACR was calculated with these two parameters [UACR $=$ urinary albumin $\times 1000 /$ (urinary creatinine $\times 0.113)]$.

\section{Echocardiography}

Echocardiograms were performed by using a commercially available echocardiography (Acuson Sequoia 218, Siemens, Germany) with a 2.5 or $3.5 \mathrm{MHz}$ transducer according to the recommendations of the American Society of Echocardiography $[13,14]$. Two-dimensional and Doppler images were obtained in the parasternal long and short axes and the apical 4- and 2chamber long-axis views. M-mode echocardiograms of the left ventricle $(\mathrm{LV})$ were recorded from the parasternal long-axis view. All recordings included at least 3 cardiac cycles and were digitally stored for off-line analysis. Left ventricular end-diastolic diameter (LVEDD), left ventricular end-systolic diameter (LVESD), interventricular septal thickness (IVST) and posterior wall thickness (PWT) were measured by M-mode or 2-dimensional echocardiography from the parasternal long axis view. Left ventricular mass (grams) was calculated as $0.80 \times(1.04 \times($ IVST + LVEDD + PWT $\left.)^{3}-(\text { LVEDD })^{3}\right)+0.6$ according to Devereux et al [15], which was further divided by body surface area (BSA) as left ventricular mass index (LVMI). Left ventricular ejection fraction (LVEF) was calculated from LV end-systolic and end-diastolic volumes (LVESV and LVEDV) measured from the apical 4- and 2-chambers views, using the modified biplane Simpson's method. Left atrial (LA) volume was measured with the same method, and was indexed to BSA as the LA volume index (LAVI). Doppler echocardiographic recordings were performed by pulsed wave Doppler with the sample volume at the tips of the mitral valve in the apical 4-chamber view. Peak early (E) and late (A) diastolic velocities, the E/A ratio, and the deceleration time (DT) of early diastolic velocity were measured as indicators of $\mathrm{LV}$ end-diastolic pressure. Assessment of peak early (E') and late (A') diastolic mitral annular velocity was performed by pulsed wave tissue Doppler imaging (TDI) of the lateral wall in the apical 4-chamber view.

\section{Criteria for diagnosis of LVDD}

As recommended by the Heart Failure and Echocardiography Associations of European Society of Cardiology (ESC), both conventional and TDI echocardiographic techniques were used for diagnosis of LVDD [3]. In the present study, the LVDD diagnosis was made according to the criteria proposed by ESC [3] and to those adopted by Zhang et al in their study [16] with minor modifications. LVDD was considered to be present if any of the 
following criteria were met: (1) E/E' $>8$; (2) E/A $<0.5$ and DT $>$ 280ms; (3) LVMI > $149 \mathrm{~g} / \mathrm{m}^{2}$ (male) or LVMI > $122 \mathrm{~g} / \mathrm{m}^{2}$ (female); or (4) LAVI $>40 \mathrm{ml} / \mathrm{m}^{2}$.

\section{Classification of severity of LVDD}

There are not uniformly recommended classifications for different degrees of LVDD. ESC guidelines in 2012 recommended $125 \mathrm{pg} / \mathrm{ml}$ of NT-proBNP as exclusion criteria of heart failure [5], while $220 \mathrm{pg} / \mathrm{ml}$ of NT-proBNP was previously shown to have positive predictive value of LVDD in diagnosis of HFPEF [3]. Therefore we chose 125 and $220 \mathrm{pg} / \mathrm{ml}$ as cut-off values to define mild LVDD with NT-proBNP $<125 \mathrm{pg} / \mathrm{ml}$, moderate LVDD with NT-proBNP between 125 and $220 \mathrm{pg} / \mathrm{ml}$, and severe LVDD with NT-proBNP $\geq 220 \mathrm{pg} / \mathrm{ml}$, respectively.

\section{Statistical analysis}

Participants were divided into two groups according to left ventricular diastolic function: normal diastolic function group and subjects with LVDD. Comparisons between the two groups were performed using $t$ tests or Wilcoxon rank sum tests for continuous variables and chi-square tests for categorical variables. Comparisons of LVDD prevalence among tertiles of the renal parameter were analyzed by Pearson chi-square tests. Further pairwise comparisons used chi-square tests and Bonferroni method to judge the significance of differences. Considering that the parameters do not obey the bivariate normal distribution, we analyzed the relationship of renal parameters with echocardiographic indexes by Spearman correlation analysis and scatter plot. Logistic multivariate regression analysis was used to further investigate the relationship of renal parameters with LVDD and its severity. Variables adjusted in the models of logistic analysis included demographic variables (age, gender), clinical measures (BMI, heart rate, SBP), risk factors (hypertension, diabetes, dyslipidemia, smoking), cardiac co-morbidities (CHD, atrial fibrillation), biochemical parameters (FBG, NT-proBNP), and LVEF. All analyses were performed with Stata version 11.0 (College Station, TX, USA). $P$ values less than 0.05 were considered to represent significance.

\section{Results}

\section{Characteristics of participants}

LVDD was diagnosed in $464(39.8 \%)$ subjects out of the 1166 participants. Compared to participants without LVDD, subjects with it were more often female, more likely to have CHD, atrial fibrillation and hypertension, while less likely to smoke. Lower heart rate but higher levels of urea, urea-to-creatinine ratio, UACR and NT-proBNP were found in subjects with LVDD. Age, BMI, SBP, creatinine, eGFR and LVEF were similar between subjects with or without LVDD (Table 1).

\section{Prevalence of LVDD in relation to different renal parameters}

The prevalence of LVDD increased in proportion to increasing values of serum urea $(P=0.05)$, urea-to-creatinine ratio $(P=0.005)$ and UACR $(P=0.029)$ (Figure 1). The prevalence of LVDD was significantly higher in subjects with serum urea $(P=0.029)$, ureato-creatinine ratio $(P=0.001)$ and $\operatorname{UACR}(P=0.008)$ located in the top tertile than in the bottom. This trend was not observed with respect to creatinine and eGFR (Data not shown).
Relationship of renal parameters with echocardiographic indexes

Serum urea (Figure 2), urea-to-creatinine ratio (Figure 3) and UACR (Figure 4) were negatively correlated to E/A ratio and positively correlated to LAVI. Besides, UACR was positively correlated to E/E' ratio (Figure 4).

\section{Association of renal parameters with presence and severity of LVDD}

Logistic univariate analysis showed that serum urea [odds ratio (OR) 1.12, 95\% confidence interval (CI) 1.04-1.20], urea-tocreatinine ratio (OR 3.02, 95\% CI 1.56-5.86) and UAGR (OR 1.30, 95\% CI 1.05-1.60) were associated with LVDD in this cohort. After adjusted for confounders, urea-to-creatinine ratio remained as an independent correlate of LVDD (Table 2). Neither serum creatinine nor eGFR correlated with LVDD before or after adjustment. Table $\mathbf{2}$ also showed that serum urea, creatinine, eGFR and UACR were all independently correlated to the advanced LVDD in the multivariate logistic analysis. Parallely, these parameters were correlated to NT-proBNP level (Table 3).

\section{Subgroup analysis in participants with normal renal function}

Most participants in community have normal renal function. So further analysis was made in a subgroup with eGFR $>60 \mathrm{ml} /$ $\mathrm{min} / 1.73 \mathrm{~m}^{2}$. In this subgroup, urea-to-creatinine ratio was still independently correlated to LVDD. While creatinine was negatively and eGFR was positively correlated to LVDD (Table 4).

\section{Discussion}

In the present study, we found for the first time in our knowledge that higher levels of serum urea, urea-to-creatinine ratio and UACR were correlated to increasing prevalence of LVDD in a community-based elderly population of China, and this was supported by their negative correlations to $\mathrm{E} / \mathrm{A}$ ratio and positive correlations to LAVI and E/E'. Moreover, urea-tocreatinine ratio was an independent correlate of LVDD. Thus, renal function has proved to be closely linked with LVDD in this community-based elderly population.

Although serum urea has been demonstrated to be predictive of adverse outcome in HFPEF patients [17,18], to the best of our knowledge, its relationship with LVDD in conjunction with other measures of renal function has not been investigated in the general elderly population. Traditionally, serum urea has been considered as a less specific marker of renal function than GFR, since it is affected by extra-renal factors like protein intake and catabolism [19]. However, serum urea may rise independently of changes in GFR because of enhanced proximal and distal tubular reabsorption by the effect of arginine-vasopressin (AVP) on the urea transporter under neurohormonal activation [19-21]. Recently, McKie et al reported that patients with preclinical diastolic dysfunction showed impaired renal cyclic guanosine monophosphate (cGMP) activation which contributed to impaired natriuresis in response to volume expansion [22]. The impaired natriuresis indicates higher reabsorption of urea and increasing serum urea concentration. These previous findings about the cardio-renal response suggest a possible explanation for the association between higher urea levels and LVDD observed in the present study. Furthermore, in the work by McKie et al [22], impaired cGMP activation and natriuresis were not paralleled by increased E/E', which is consistent with our finding that serum urea was related with E/A and LAVI but not E/E'. 
Table 1. Characteristics of participants according to presence and absence of LVDD.

\begin{tabular}{|c|c|c|c|c|}
\hline & Total & Without LVDD & With LVDD & $P$ value* \\
\hline \multicolumn{5}{|l|}{ Demographics } \\
\hline $\mathrm{n}$ & 1166 & 702 & 464 & \\
\hline Age (yrs) & $72.7 \pm 4.8$ & $72.7 \pm 4.7$ & $72.9 \pm 4.9$ & 0.658 \\
\hline Female (\%) & 59.5 & 55.7 & 65.3 & 0.001 \\
\hline Heart rate (bpm) & $74 \pm 14$ & $75 \pm 14$ & $72 \pm 15$ & $<0.001$ \\
\hline BMI $\left(k g / m^{2}\right)$ & $22.3 \pm 2.6$ & $22.2 \pm 2.7$ & $22.3 \pm 2.6$ & 0.717 \\
\hline SBP $(\mathrm{mmHg})$ & $131 \pm 14$ & $130 \pm 13$ & $131 \pm 14$ & 0.184 \\
\hline DBP $(\mathrm{mmHg})$ & $80 \pm 9$ & $80 \pm 8$ & $80 \pm 9$ & 0.268 \\
\hline \multicolumn{5}{|l|}{ Co-morbidities } \\
\hline CHD (\%) & 3.5 & 2.6 & 5.0 & 0.030 \\
\hline Atrial fibrillation (\%) & 4.6 & 2.1 & 8.4 & $<0.001$ \\
\hline Stroke (\%) & 2.6 & 3.0 & 1.9 & 0.267 \\
\hline Hypertension (\%) & 44.4 & 41.7 & 48.5 & 0.023 \\
\hline Diabetes (\%) & 12.0 & 12.3 & 11.6 & 0.753 \\
\hline Dyslipidemia (\%) & 43.1 & 43.2 & 42.9 & 0.926 \\
\hline Smoking (\%) & 30.2 & 33.6 & 25.0 & 0.002 \\
\hline Obesity (\%) & 32.6 & 31.5 & 34.3 & 0.321 \\
\hline \multicolumn{5}{|l|}{ Laboratory variables } \\
\hline Urea $(\mathrm{mmol} / \mathrm{l})$ & $6.3 \pm 1.7$ & $6.2 \pm 1.6$ & $6.5 \pm 1.8$ & 0.003 \\
\hline Creatinine $(\mu \mathrm{mol} / \mathrm{l})$ & $64(48-80)$ & $64(50-81)$ & $62(47-80)$ & 0.098 \\
\hline Urea-to-creatinine ratio & $96(73-126)$ & $92(72-122)$ & $102(77-135)$ & $<0.001$ \\
\hline Uric acid ( $\mu \mathrm{mol} / \mathrm{l})$ & $339.8 \pm 94.9$ & $338.7 \pm 94.5$ & $341.5 \pm 95.5$ & 0.762 \\
\hline eGFR $\left(\mathrm{ml} / \mathrm{min} / 1.73 \mathrm{~m}^{2}\right)$ & $108(79-144)$ & $106(78-142)$ & $111(80-147)$ & 0.320 \\
\hline UACR $(\mu \mathrm{g} / \mathrm{mg} \mathrm{Cr})$ & $14.0(6.1-33.3)$ & $12.8(5.7--30.6)$ & $16.5(7.0-39.2)$ & 0.008 \\
\hline FBG $(\mathrm{mmol} / \mathrm{l})$ & $5.9 \pm 1.5$ & $5.9 \pm 1.6$ & $5.9 \pm 1.4$ & 0.500 \\
\hline $\mathrm{TC}(\mathrm{mmol} / \mathrm{l})$ & $4.9 \pm 1.0$ & $4.9 \pm 1.0$ & $4.9 \pm 1.0$ & 0.479 \\
\hline TG $(\mathrm{mmol} / \mathrm{l})$ & $1.7 \pm 1.0$ & $1.7 \pm 1.1$ & $1.6 \pm 1.0$ & 0.440 \\
\hline LDL-C (mmol/l) & $3.2 \pm 1.2$ & $3.2 \pm 1.2$ & $3.2 \pm 1.3$ & 0.885 \\
\hline $\mathrm{HDL}-\mathrm{C}(\mathrm{mmol} / \mathrm{l})$ & $1.4 \pm 0.4$ & $1.4 \pm 0.4$ & $1.4 \pm 0.3$ & 0.884 \\
\hline NT-proBNP (pg/ml) & $110.6(65.2-193.7)$ & $96.3(57.8-173.6)$ & $130.4(77.1-232.8)$ & $<0.001$ \\
\hline LVEF (\%) & $64 \pm 9$ & $65 \pm 8$ & $64 \pm 10$ & 0.660 \\
\hline
\end{tabular}

Values of creatinine, urea-to-creatinine ratio, eGFR, UACR and NT-proBNP are median (interquartile), other values are mean \pm SD or $\%$.

$\mathrm{HR}$, heart rate; BMI, body mass index; SBP, systolic blood pressure; DBP, diastolic blood pressure; CHD, coronary heart disease; eGFR, estimated glomerular filtration rate; UACR, urinary albumin-to-creatininie ratio; FBG, fasting blood glucose; TC, total cholesterol; TG, triglycerides; LDL-C, low density lipoprotein cholesterol; HDL-C, high density lipoprotein cholesterol; NT-proBNP, N-terminal pro-B type natriuretic peptide; LVEF, left ventricular ejection fraction.

*Compared between subjects with and without LVDD.

doi:10.1371/journal.pone.0088638.t001

The serum urea-to-creatinine ratio has been extensively used for the differentiation of "pre-renal" dysfunction from intrinsic renal parenchymal disease [23], and has been suggested positively correlated with poor outcomes in patients with acute or chronic HF [24-26]. Neuroendocrine activation might also serve as one of the potential reasons for urea-to-creatinine ratio elevation in prerenal ischemia [20,21]. Therefore, the aforementioned mechanism with regard to urea and LVDD could also interpret the independent relation of urea-to-creatinine ratio with LVDD. Our findings about a positive relation of urea and urea-tocreatinine ratio with LVDD but lack of relation of creatinine and eGFR with LVDD may suggest a neuroendocrine activation status in LVDD subjects. We hypothesize that serum urea and urea-tocreatinine ratio are more sensitive than eGFR and creatinine to represent the early neuroendocrine activation in LVDD, when the cardiac output has not reduced yet and glomerular filtration is still normal. Further studies are warranted to test these relationships and the hypothesis.

Available findings about urinary albumin excretion (UAE) and its relation with diastolic function remain conflicting [27-30]. The CHARM study found that the prevalence of increased UACR, a convenient method for detection of UAE [27], was similar in HFPEF (41\%) and HFREF patients [28], whereas HARVEST study reported that UAE was unrelated to LV mass in subjects with stage 1 hypertension [29]. Furthermore, Post et al found that elevated random spot UACR was a marker of increased LV mass [30]. In the present study, we found 1) the prevalence of LVDD increased with the increasing UACR, 2) UACR was related to echocardiographic indexes like E/E', E/A and LAVI, and 3) UACR was independently associated with the severity of LVDD. Therefore our findings not only extend previous studies by Post et al but also suggest LVDD as pathophysiologic link between UAE 

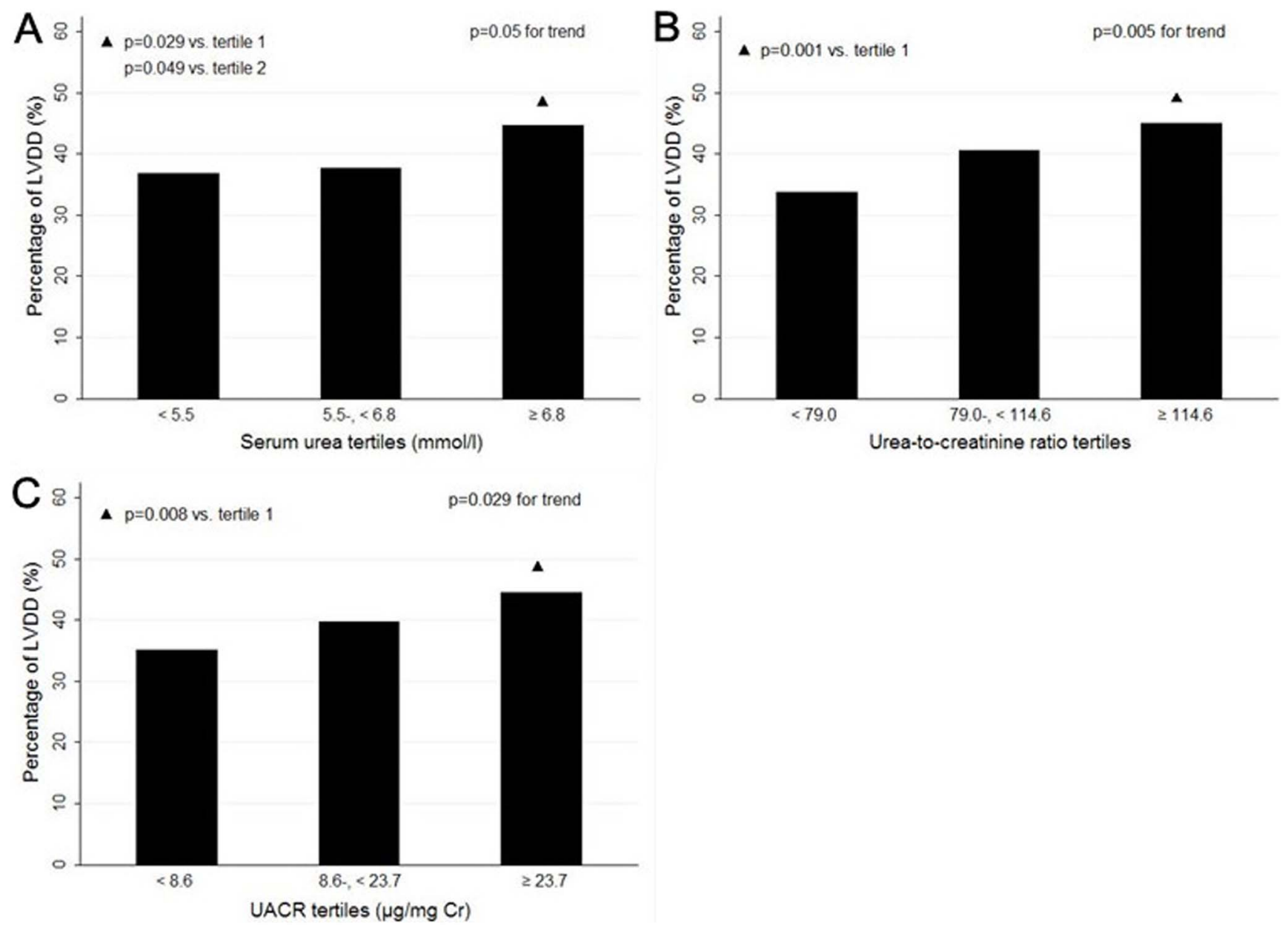

Figure 1. Prevalence of LVDD according to serum urea, urea-to-creatinine ratio, and UACR. The prevalence of LVDD is $36.9 \%, 37.6 \%$ and $44.6 \%$ in tertile 1,2 and 3 of serum urea respectively. It is $33.8 \%, 40.5 \%$ and $45.1 \%$ for urea-to-creatinine ratio and $35.1 \%, 39.7 \%$ and $44.5 \%$ for UACR, respectively. LVDD, left ventricular diastolic dysfunction; UACR, urinary albumin-to-creatinine ratio. doi:10.1371/journal.pone.0088638.g001
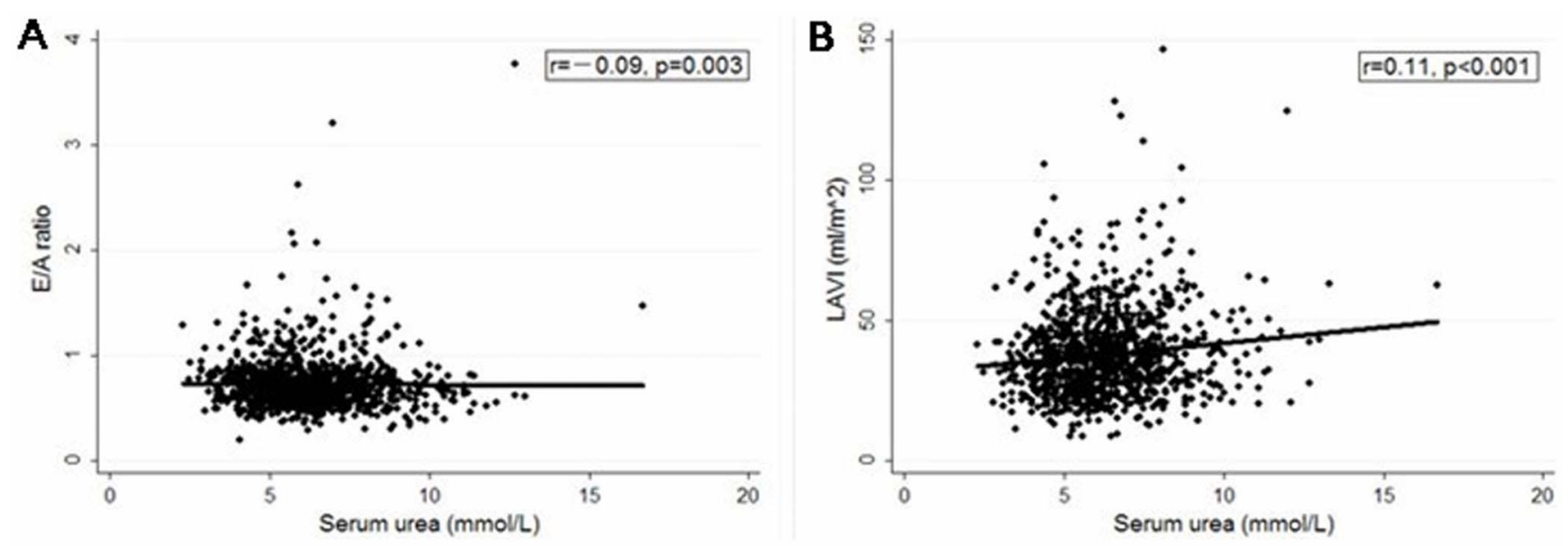

Figure 2. Relationship between serum urea and echocardiographic indexes (E/A and LAVI). A) Serum urea was negatively correlated to E/ A ratio. B) Serum urea was positively correlated to LAVI. LAVI, left atrial volume index. doi:10.1371/journal.pone.0088638.g002 

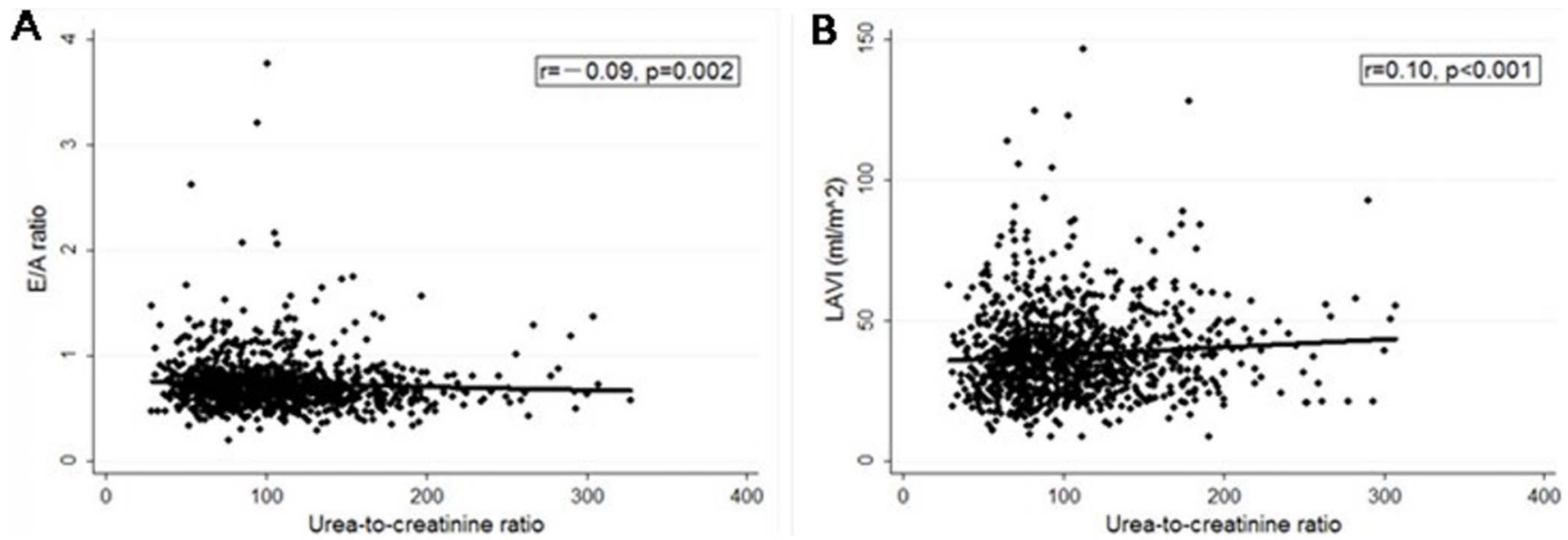

Figure 3. Relationship between urea-to-creatinine ratio and echocardiographic indexes (E/A and LAVI). A) Urea-to-creatinine ratio was negatively correlated to E/A ratio. B) Urea-to-creatinine ratio was positively correlated to LAVI. LAVI, left atrial volume index. doi:10.1371/journal.pone.0088638.g003
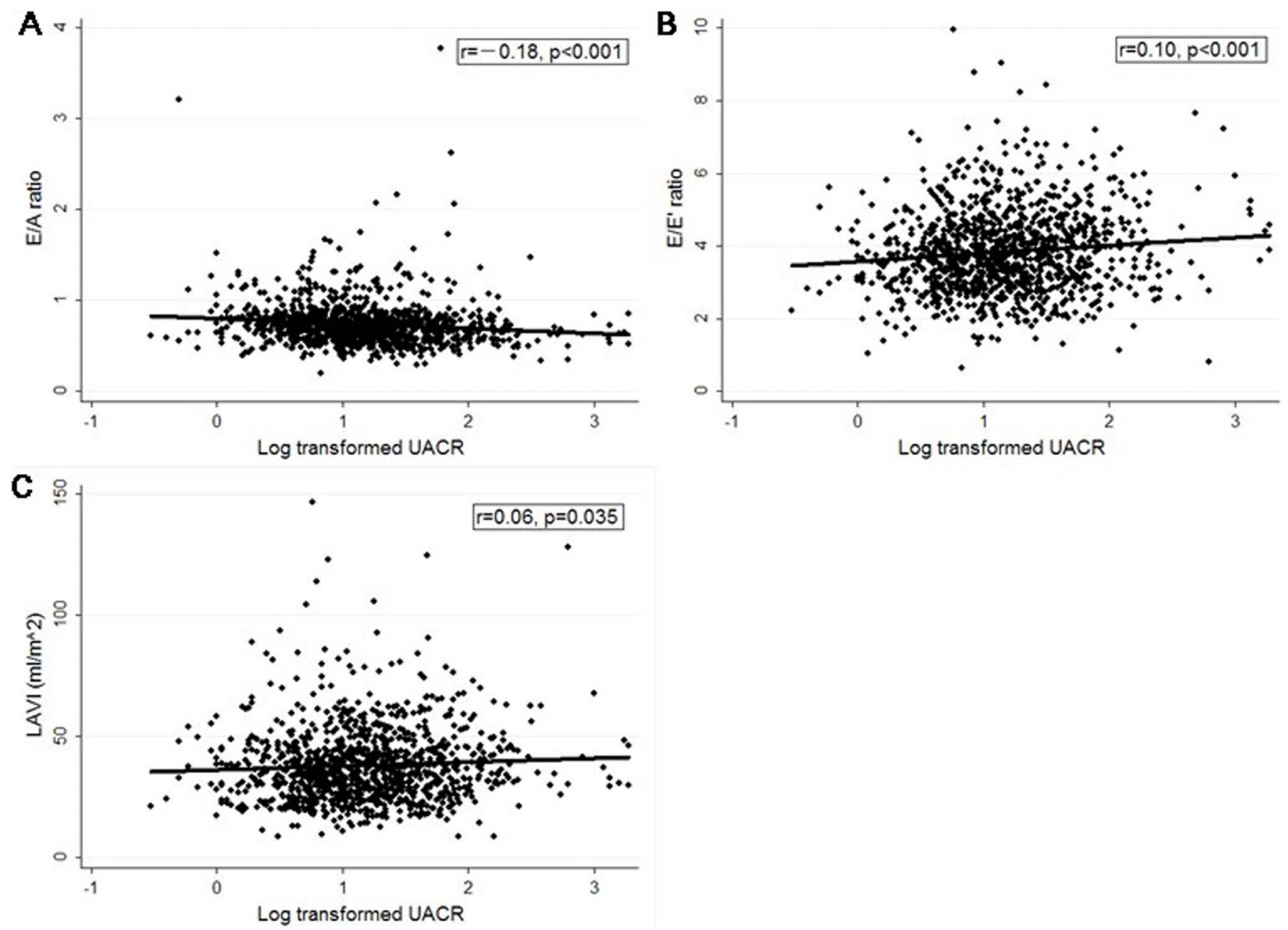

Figure 4. Relationship between UACR and echocardiographic indexes (E/A, E/E' and LAVI). A) UACR was negatively correlated to E/A ratio. B) UACR was positively correlated to LAVI. C) UACR was also positively correlated to E/E' ratio. UACR, urinary albumin-to-creatinine ratio; LAVI, left atrial volume index.

doi:10.1371/journal.pone.0088638.g004 
Table 2. The association of biochemical renal parameters with LVDD and severity of LVDD.

\begin{tabular}{|c|c|c|c|c|c|c|}
\hline \multirow[t]{2}{*}{ Variable $* * *$} & \multicolumn{3}{|c|}{ LVDD* } & \multicolumn{3}{|c|}{ Advanced LVDD** } \\
\hline & OR & $95 \% \mathrm{Cl}$ & $P$ value & OR & $95 \% \mathrm{Cl}$ & $P$ value \\
\hline Urea $(\mathrm{mmol} / \mathrm{l})$ & 1.07 & $0.99-1.16$ & 0.087 & 1.18 & $1.03-1.34$ & 0.013 \\
\hline Creatinine $(\mu \mathrm{mol} / \mathrm{l})$ & 0.47 & $0.21-1.06$ & 0.070 & 6.53 & $1.70-25.02$ & 0.006 \\
\hline $\begin{array}{l}\text { Urea-to-creatinine } \\
\text { ratio }\end{array}$ & 2.82 & $1.34-5.95$ & 0.006 & 0.58 & $0.18-1.94$ & 0.379 \\
\hline $\begin{array}{l}\text { eGFR }(\mathrm{ml} / \mathrm{min} / \\
\left.1.73 \mathrm{~m}^{2}\right)\end{array}$ & 1.85 & $0.95-3.60$ & 0.070 & 0.22 & $0.07-0.65$ & 0.006 \\
\hline UACR $(\mu \mathrm{g} / \mathrm{mg} \mathrm{Cr})$ & 1.10 & $0.86-1.40$ & 0.451 & 2.15 & $1.42-3.24$ & $<0.001$ \\
\hline \multicolumn{7}{|c|}{$\begin{array}{l}\text { OR, odds ratio; } \mathrm{Cl} \text {, confidence interval. Other abbreviations as in Table } 1 . \\
\text { *Adjusted for age, gender, heart rate, BMI, SBP, smoking status, presence or } \\
\text { absence of hypertension, diabetes mellitus, CHD, and atrial fibrillation; FBG, NT- } \\
\text { proBNP and LVEF. NT-proBNP is log transformed before entering models. } \\
\text { **Adjusted the same parameters except NT-proBNP. } \\
\text { ***Per } 1 \text { unit increase in urea values; per } 1 \text { log unit increase in creatinine, urea- } \\
\text { to-creatinine ratio, eGFR and UACR values. } \\
\text { doi:10.1371/journal.pone. } 0088638 . t 002\end{array}$} \\
\hline
\end{tabular}

and mortality [31]. Endothelial dysfunction might represent a contributory mechanism to this association since it has been proved to be associated with both UAE $[32,33]$ and LVDD [3436].

UACR is suggested not specific for kidney disease but a marker of systemic inflammation and microvascular damage including endothelial dysfunction [37,38], which is an predominant early step in the process of clinical overt cardiovascular disease [39]. Nevertheless, eGFR mainly reflects the hemodynamic status of the kidney. Since isolated LVDD was found associated with endothelial dysfunction [34-36] but unlikely to cause decline of cardiac output and renal macrovascular perfusion in the early stage, it could be understood why LVDD was correlated with UACR but not with eGFR in the present study.

Both population-based studies [40,41] and studies on hospitalized HFPEF patients $[42,43]$ support our choice of NT-proBNP as tool to grade LVDD since in both settings NT-proBNP was found to be directly associated with LVDD severity. The relationship of renal parameters with NT-proBNP uncovered in our study, together with other studies demonstrating that NT-proBNP levels are affected by declining renal function [44-46], are in keeping with the theory that the clearance of NT-proBNP occurs solely in the kidney [47]. This finding also indicates that when NT-proBNP is employed to evaluate the presence or severity of LVDD, renal

Table 3. The association of biochemical renal parameters with NT-proBNP.

\begin{tabular}{|c|c|c|}
\hline \multirow[t]{2}{*}{ Variable } & \multicolumn{2}{|c|}{ NT-proBNP } \\
\hline & $r^{*}$ & $P$ value \\
\hline Urea (mmol/l) & 0.12 & $<0.001$ \\
\hline Creatinine $(\mu \mathrm{mol} / \mathrm{l})$ & 0.07 & 0.021 \\
\hline Urea-to-creatinine ratio & 0.01 & 0.667 \\
\hline eGFR $\left(\mathrm{ml} / \mathrm{min} / 1.73 \mathrm{~m}^{2}\right)$ & -0.13 & $<0.001$ \\
\hline UACR $(\mu \mathrm{g} / \mathrm{mg} \mathrm{Cr})$ & 0.18 & $<0.001$ \\
\hline
\end{tabular}

Table 4. The association of renal parameters with LVDD in subpopulation with eGFR $>60 \mathrm{ml} / \mathrm{min} / 1.73 \mathrm{~m}^{2}$.

\begin{tabular}{|c|c|c|c|c|c|c|}
\hline \multirow[t]{2}{*}{ Variable } & \multicolumn{3}{|c|}{ Unadjusted } & \multicolumn{3}{|c|}{ Adjusted* } \\
\hline & OR** & $95 \% \mathrm{Cl}$ & $P$ value & e OR** & $95 \% \mathrm{Cl}$ & $P$ value \\
\hline Urea $(\mathrm{mmol} / \mathrm{l})$ & 1.10 & $1.01-1.19$ & 0.021 & 1.07 & $0.98-1.16$ & 0.138 \\
\hline Creatinine $(\mu \mathrm{mol} / \mathrm{l})$ & 0.28 & $0.11-0.69$ & 0.006 & 0.33 & $0.12-0.90$ & 0.031 \\
\hline $\begin{array}{l}\text { Urea-to-creatinine } \\
\text { ratio }\end{array}$ & 3.93 & $1.89-8.15$ & $<0.001$ & 3.06 & $1.35-6.92$ & 0.007 \\
\hline $\begin{array}{l}\text { eGFR }(\mathrm{ml} / \mathrm{min} / \\
\left.1.73 \mathrm{~m}^{2}\right)\end{array}$ & 2.18 & $1.00-4.72$ & 0.049 & 2.48 & $1.09-5.64$ & 0.031 \\
\hline UACR $(\mu \mathrm{g} / \mathrm{mg} \mathrm{Cr})$ & 1.26 & $1.01-1.59$ & 0.045 & 1.10 & $0.84-1.43$ & 0.491 \\
\hline
\end{tabular}

$\mathrm{OR}$, odds ratio; $\mathrm{Cl}$, confidence interval.

${ }^{*}$ Adjusted for age, gender, heart rate, BMI, SBP, smoking status, presence or absence of hypertension, diabetes mellitus, CHD, and atrial fibrillation; FBG, NTproBNP and LVEF. NT-proBNP is log transformed before entering models. Abbreviations as in Table 1.

**OR is per 1 unit increase in urea values; per 1 log unit increase in creatinine, urea-to-creatinine ratio, eGFR and UACR values.

doi:10.1371/journal.pone.0088638.t004

function should be considered because both decreased clearance of kidney and increased production due to LVDD could lead to the rise of NT-proBNP.

The subgroup analysis in subjects with normal renal function $\left(\mathrm{eGFR}>60 \mathrm{ml} / \mathrm{min} / 1.73 \mathrm{~m}^{2}\right)$ revealed, for the first time, an interesting result that eGFR was independently and positively correlated to LVDD. It has been demonstrated that there is a significant and positive correlation between GFR and LV mass in non-diabetic patients with mild to moderate hypertension [48], concurring with our result to some extent. Considering these findings, we assume that glomerular hyperfiltration may be linked to LVDD. Nevertheless, more studies are still needed to confirm this assumption.

The present study has some limitations. First, specific data on symptoms or signs related to $\mathrm{HF}$ were not available. Additionally, we did not assess $\mathrm{Ar}_{\mathrm{d}}-\mathrm{A}_{\mathrm{d}}$ because of constraints in echocardiographic examination time per participant. $\mathrm{Ar}_{\mathrm{d}}-\mathrm{A}_{\mathrm{d}}$ was still kept in the latest European Consensus document as a second-line criteria of LVDD [3]. However, studies suggested that $\mathrm{Ar}_{\mathrm{d}}-\mathrm{A}_{\mathrm{d}}$ was often obtained less successfully $(49 \%-84 \%)$ in clinic than other diastolic measures [49,50], and pulmonary venous inflow had more interreader variability than mitral valve inflow and annular tissue Doppler [50]. Emery et al also found that even in hospitalized patients, very few of them presented $\mathrm{Ar}_{\mathrm{d}}-\mathrm{A}_{\mathrm{d}}>30 \mathrm{~ms}$, and the measure had minimal sensitivity [49]. All of these indicated that $\mathrm{Ar}_{\mathrm{d}}-\mathrm{A}_{\mathrm{d}}$ probably contribute little to overall diastolic function assessment.

\section{Conclusions}

In summary, the present study suggests that higher levels of serum urea, urea-to-creatinine ratio and UACR are linked with increasing prevalence of LVDD, and urea-to-creatinine ratio is an independent correlate of LVDD. Although serum creatinine and eGFR are not associated with LVDD in the whole community cohort, they, together with serum urea and UACR, are independently associated with advanced LVDD in parallel with increased NT-proBNP level. Our findings contribute to further understanding of the cardio-renal relationship in the elderly population. 


\section{Acknowledgments}

We thank all the community residents participating in the study, and staffs providing help from the Fengjing Community Health Center.

\section{Author Contributions}

Conceived and designed the experiments: JMZ XTC XJJ KH MF JBG. Performed the experiments: XTG XJJ JZ HYZ BXT JC HMZ AJS. Analyzed the data: XTC XJJ JZ KH MF HH. Contributed reagents/ materials/analysis tools: HYZ BXT HH AJS . Wrote the paper: XTC JMZ KH MF HH JBG.

\section{References}

1. Owan TE, Hodge DO, Herges RM, Jacobsen SJ, Roger VL, et al. (2006) Trends in prevalence and outcome of heart failure with preserved ejection fraction. $\mathrm{N}$ Engl J Med 355: 251-259.

2. Zile MR, Baicu CF, Gaasch WH. (2004) Diastolic heart failure-abnormalities in active relaxation and passive stiffness of the left ventricle. N Engl J Med 350: 1953-1959.

3. Paulus WJ, Tschöpe C, Sanderson JE, Rusconi C, Flachskampf FA, et al. (2007) How to diagnose diastolic heart failure: a consensus statement on the diagnosis of heart failure with normal left ventricular ejection fraction by the Heart Failure and Echocardiography Associations of the European Society of Cardiology. Eur Heart J 28: 2539-2550.

4. Owan TE, Redfield MM. (2005) Epidemiology of diastolic heart failure. Prog Cardiovasc Dis 47: 320-332.

5. McMurray JJ, Adamopoulos S, Anker SD, Auricchio A, Böhm M, et al. (2012) ESC Guidelines for the diagnosis and treatment of acute and chronic heart failure 2012: The Task Force for the Diagnosis and Treatment of Acute and Chronic Heart Failure 2012 of the European Society of Cardiology. Developed in collaboration with the Heart Failure Association (HFA) of the ESC. Eur Heart J 33: 1787-1847.

6. Kerzner R, Gage BF, Freedland KE, Rich MW. (2003) Predictors of mortality in younger and older patients with heart failure and preserved or reduced left ventricular ejection fraction. Am Heart J 146: 286-290.

7. Ahmed A, Rich MW, Sanders PW, Perry GJ, Bakris GL, et al. (2007) Chronic kidney disease associated mortality in diastolic versus systolic heart failure: a propensity matched study. Am J Cardiol 99: 393-398.

8. Bruch C, Rothenburger M, Gotzmann M, Wichter T, Scheld HH, et al. (2007) Chronic kidney disease in patients with chronic heart failure-impact on intracardiac conduction, diastolic function and prognosis. Int J Cardiol 118 : 375-380.

9. Sato B, Yoshikawa D, Ishii H, Suzuki S, Inoue Y, et al. (2013) Relation of plasma indoxyl sulfate levels and estimated glomerular filtration rate to left ventricular diastolic dysfunction. Am J Cardiol 111: 712-716.

10. Nishio M, Sakata Y, Mano T, Ohtani T, Takeda Y, et al. (2008) Difference of clinical characteristics between hypertensive patients with and without diastolic heart failure: the roles of diastolic dysfunction and renal insufficiency. Hypertens Res 31: 1865-1872.

11. Ge JB, Zhou JM, Jin XJ. (2012) Shanghai Heart Health Study: design and objectives. Shanghai Medical Journal 35: 1-6.

12. Ma YC, Zuo L, Chen JH, Luo Q, Yu XQ, et al. (2006) Modified glomerular filtration rate estimating equation for Chinese patients with chronic kidney disease. J Am Soc Nephrol 17: 2937-2944.

13. Gottdiener JS, Bednarz J, Devereux R, Gardin J, Klein A, et al. (2004) American Society of Echocardiography recommendations for use of echocardiography in clinical trials. J Am Soc Echocardiogr 17: 1086-1119.

14. Nagueh SF, Appleton CP, Gillebert TC, Marino PN, Oh JK, et al. (2009) Recommendations for the evaluation of left ventricular diastolic function by echocardiography. J Am Soc Echocardiogr 22: 107-133.

15. Devereux RB, Alonso DR, Lutas EM, Gottlieb GJ, Campo E, et al. (1986) Echocardiographic assessment of left ventricular hypertrophy: comparison to necropsy findings. Am J Cardiol 57: 450-458.

16. Zhang Y, Safar ME, Iaria P, Agnoletti D, Protogerou AD, et al. (2010) Prevalence and prognosis of left ventricular diastolic dysfunction in the elderly: The PROTEGER Study. Am Heart J 160: 471-478.

17. Feola M, Aspromonte N, Canali C, Ceci V, Giovinazzo P, et al. (2005) Prognostic value of plasma brain natriuretic peptide, urea nitrogen, and creatinine in outpatients $>70$ years of age with heart failure. Am J Cardiol 96: $705-709$.

18. Shenkman HJ, Zareba W, Bisognano JD. (2007) Comparison of prognostic significance of amino-terminal pro-brain natriuretic Peptide versus blood urea nitrogen for predicting events in patients hospitalized for heart failure. Am J Cardiol 99: 1143-1145.

19. Schrier RW. (2008) Blood urea nitrogen and serum creatinine: not married in heart failure. Circ Heart Fail 1: 2-5.

20. Schrier RW, Abraham WT. (1999) Hormones and hemodynamics in heart failure. N Engl J Med 341: 577-585.

21. Schrier RW. (2006) Role of diminished renal function in cardiovascular mortality: marker or pathogenetic factor? J Am Coll Cardiol 47: 1-8.

22. McKie PM, Schirger JA, Costello-Boerrigter LC, Benike SL, Harstad LK, et al. (2011) Impaired natriuretic and renal endocrine response to acute volume expansion in pre-clinical systolic and diastolic dysfunction. J Am Coll Cardiol 58: 2095-2103.

23. Cecil RL, Goldman L, Ausiello DA. (2008) Cecil medicine. Philadelphia: Saunders Elsevier.
24. Aronson D, Mittleman MA, Burger AJ. (2004) Elevated blood urea nitrogen level as a predictor of mortality in patients admitted for decompensated heart failure. Am J Med 116: 466-473.

25. Smith GL, Shlipak MG, Havranek EP, Foody JM, Masoudi FA, et al. (2006) Serum urea nitrogen, creatinine, and estimators of renal function-mortality in older patients with cardiovascular disease. Arch Intern Med 166: 1134-1142.

26. Lin HJ, Chao CL, Chien KL, Ho YL, Lee CM, et al. (2009) Elevated blood urea nitrogen-to-creatinine ratio increased the risk of hospitalization and all-cause death in patients with chronic heart failure. Clin Res Cardiol 98: 487-492.

27. National Kidney Foundation. (2002) K/DOQI clinical practice guidelines for chronic kidney disease: evaluation classification and stratification. Am J Kidney Dis 39: S1-S266.

28. Jackson CE, Solomon SD, Gerstein HC, Zetterstrand S, Olofsson B, et al; CHARM Investigators and Committees. (2009) Albuminuria in chronic heart failure: prevalence and prognostic importance. Lancet 374: 543-550.

29. Palatini P, Graniero GR, Mormino P, Mattarei M, Sanzuol F, et al. (1996) Prevalence and clinical correlates of microalbuminuria in stage I hypertension. Results from the Hypertension and Ambulatory Recording Venetia Study (HARVEST Study). Am J Hypertens 9: 334-341.

30. Post WS, Blumenthal RS, Weiss JL, Levine DM, Thiemann DR, et al. (2000) Spot urinary albumin-creatinine ratio predicts left ventricular hypertrophy in young hypertensive African-American men. Am J Hypertens 13: 1168-1172.

31. Redfield MM, Jacobsen SJ, Burnett JC Jr, Mahoney DW, Bailey KR, et al. (2003) Burden of systolic and diastolic ventricular dysfunction in the community:appreciating the scope of the heart failure epidemic. JAMA 289: 194-202.

32. Stehouwer CD, Nauta JJ, Zeldenrust GC, Hackeng WH, Donker AJ, et al. (1992) Urinary albumin excretion, cardiovascular disease, and endothelial dysfunction in non-insulin-dependent diabetes mellitus. Lancet 340: 319-323.

33. Stehouwer CD, Gall MA, Twisk JW, Knudsen E, Emeis JJ, et al. (2002) Increased urinary albumin excretion, endothelial dysfunction, and chronic lowgrade inflammation in type 2 diabetes: progressive, interrelated, and independently associated with risk of death. Diabetes 51: 1157-1165.

34. Ma LN, Zhao SP, Gao M, Zhou QC, Fan P. (2000) Endothelial dysfunction associated with left ventricular diastolic dysfunction in patients with coronary heart disease. Int J Cardiol 72: 275-279.

35. Zizek B, Poredos P. (2007) Increased left ventricular mass and diastolic dysfunction are associated with endothelial dysfunction in normotensive offspring of subjects with essential hypertension. Blood Press 16: 36-44.

36. Elesber AA, Redfield MM, Rihal CS, Prasad A, Lavi S, et al. (2007) Coronary endothelial dysfunction and hyperlipidemia are independently associated with diastolic dysfunction in humans. Am Heart J 153: 1081-1087.

37. El Nahas M. (2010) Cardio-Kidney-Damage: a unifying concept. Kidney Int 78: $14-18$.

38. Malik AR, Sultan S, Turner ST, Kullo IJ. (2007) Urinary albumin excretion is associated with impaired flow- and nitroglycerin-mediated brachial artery dilatation in hypertensive adults. J Hum Hypertens 21: 231-238.

39. Abdelhafiz AH, Ahmed S, El Nahas M. (2011) Microalbuminuria: marker or maker of cardiovascular disease. Nephron Exp Nephrol 119 Suppl 1: e6-e10.

40. Kloch-Badelek M, Kuznetsova T, Sakiewicz W, Tikhonoff V, Ryabikov A, et al; European Project On Genes in Hypertension (EPOGH) Investigators. (2012) Prevalence of left ventricular diastolic dysfunction in European populations based on cross-validated diagnostic thresholds. Cardiovasc Ultrasound 10:10.

41. Abhayaratna WP, Marwick TH, Becker NG, Jeffery IM, McGill DA, et al (2006) Population-based detection of systolic and diastolic dysfunction with amino-terminal pro-B-type natriuretic peptide. Am Heart J 152: 941-948.

42. Tschöpe C, Kasner M, Westermann D, Gaub R, Poller WC, et al. (2005) The role of NT-proBNP in the diagnostics of isolated diastolic dysfunction: correlation with echocardiographic and invasive measurements. Eur Heart J 26: $2277-2284$.

43. Grewal J, McKelvie R, Lonn E, Tait P, Carlsson J, et al. (2008) BNP and NTproBNP predict echocardiographic severity of diastolic dysfunction. Eur J Heart Fail 10: 252-259.

44. Vickery S, Price CP, John RI, Abbas NA, Webb MC, et al. (2005) B-type natriuretic peptide (BNP) and amino-terminal proBNP in patients with CKD: relationship to renal function and left ventricular hypertrophy. Am J Kidney Dis 46: 610-620.

45. DeFilippi C, van Kimmenade RR, Pinto YM. (2008) Amino-terminal pro-Btype natriuretic peptide testing in renal disease. Am J Cardiol 101: 82-88.

46. van Kimmenade RR, Januzzi JL Jr, Bakker JA, Houben AJ, Rennenberg R, et al. (2009) Renal clearance of B-type natriuretic peptide and amino terminal proB-type natriuretic peptide: a mechanistic study in hypertensive subjects. J Am Coll Cardiol 53: 884-890. 
47. Panteghini M, Clerico A. (2004) Understanding the clinical biochemistry of Nterminal pro-B-type natriuretic peptide: The prerequisite for its optimal clinical use. Clin Lab 50: 325-331.

48. Schmieder RE, Messerli FH, Garavaglia G, Nunez B. (1990) Glomerular hyperfiltration indicates early target organ damage in essential hypertension. JAMA 264: 2775-2780.
49. Emery WT, Jadavji I, Choy JB, Lawrance RA. (2008) Investigating the European Society of Cardiology Diastology Guidelines in a practical scenario. Eur J Echocardiogr 9: 685-691.

50. Bess RL, Khan S, Rosman HS, Cohen GI, Allebban Z, et al. (2006) Technical aspects of diastology: why mitral inflow and tissue Doppler imaging are the preferred parameters? Echocardiography 23: 332--339. 